\title{
Correction to: Upper urinary tract urothelial carcinoma on multidetector CT: spectrum of disease
}

\author{
Osama Ali $^{1} \cdot$ Elliot K. Fishman ${ }^{1} \cdot$ Shelia Sheth ${ }^{1}$
}

Published online: 14 November 2019

○) Springer Science+Business Media, LLC, part of Springer Nature 2019

\section{Correction to: Abdominal Radiology}

https://doi.org/10.1007/s00261-019-02173-2

The original version of this article contained an error in one of the author name. The co-author name was published as "Elliot Fishman", instead it should be "Elliot K. Fishman". The original article has been corrected.

Publisher's Note Springer Nature remains neutral with regard to jurisdictional claims in published maps and institutional affiliations.

The original article can be found online at https://doi.org/10.1007/ s00261-019-02173-2.

Osama Ali

Oali4@jhmi.edu

1 Russell H. Morgan Department of Radiology and Radiological Science, Johns Hopkins School of Medicine, Johns Hopkins University, 601 N. Caroline Street/JHOC 3235A, Baltimore, MD 21287, USA 